\title{
Análise da Estrutura Organizacional e Conceitual da Educação ESPECIAL BRASILEIRA (2008-2013)

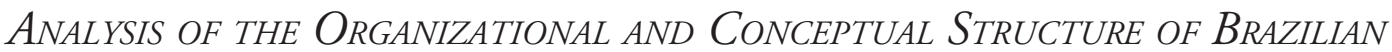 SPECIAL EDUCATION (2008-2013)
}

\author{
Franco Ezequiel HARLOS ${ }^{1}$ \\ Fátima Elisabeth DENARI ${ }^{2}$ \\ Rosimeire Maria ORLANDO ${ }^{3}$
}

\begin{abstract}
RESUMO: nesta pesquisa objetivou-se desvelar e analisar a estrutura organizacional e conceitual da Educação Especial brasileira, configurada nos documentos que orientam as políticas públicas relacionadas com esta modalidade de ensino e que foram publicados entre janeiro de 2008 e abril de 2013. Empregando-se pesquisa documental e análise categorial, efetuou-se a compilação e análise de trinta documentos apresentados no portal do Ministério de Educação como orientadores da Política Nacional de Educação Especial na Perspectiva da Educação Inclusiva. A análise da estrutura organizacional e conceitual da Educação Especial revelou a perpetuação de tradicionais contradiçôes dos discursos associados com esta modalidade de ensino.
\end{abstract}

PALAVRAS-CHAVE: Educaçăo Especial. Política Educacional. Educação Inclusiva.

ABSTRACT: In this paper, we aimed to uncover and analyze the organizational and conceptual structure of Brazilian Special Education, as it is configured by documents published from January 2008 to April 2013 that guide its public policies. We applied documentary research and thematic categorical analysis to perform the compilation and analysis of thirty documents presented by the Ministry of Education as guides for national policies on inclusive Special Education. The analysis of the organizational and conceptual structure of Special Education revealed the perpetuation of traditional contradictions of discourse associated with Special Education.

KEYWORDS: Special Education. Educational Policy. Inclusive Education.

\section{INTRODUÇÁo}

No interregno entre janeiro de 2008 e abril de 2013, decisōes Políticas provocaram reconfiguraçôes na estrutura organizacional e conceitual da Educação Especial brasileira, ou seja: reconfigurou-se o conjunto de conceitos que, definindo os elementos humanos (públicoalvo e profissionais), materiais (espaços, financiamentos e recursos de acessibilidade) e as formas operacionais (o modus operandi) da Educação Especial, nos documentos oficiais, são estrategicamente articulados para a estruturação da Educação Especial brasileira.

O documento Política Nacional de Educação Especial na perspectiva da Educação Inclusiva (PNEEPEI) (BRASIL, 2008a) constitui-se em um delineador inicial destas reconfiguraçōes, pois nele foram condensadas proposições e a caracterização de "novos" conceitos, serviços, sujeitos e espaços para Educação Especial. O documento em questão, nos

\footnotetext{
${ }^{1}$ Instituto Federal de Educação, Ciência e Tecnologia do Paraná, Departamento de Educação, Foz do Iguaçu, Paraná, Brasil. francoeh@yahoo.com.br

${ }^{2}$ Universidade Federal de São Carlos, Departamento de Psicologia, São Carlos, São Paulo, Brasil. fadenari@terra.com.br 3 Universidade Federal de São Carlos, Departamento de Psicologia, São Carlos, São Paulo, Brasil. mzeppone@gmail.com
} 
textos que o constituem, é apresentado como marco reestruturante da Educação Especial; como gênese de uma política que representaria um avanço em relação às políticas que o precederam; como porta voz da Educação Especial "na" perspectiva da educação inclusiva - como se a perspectiva nele expressa fosse a única possível e não apenas uma dentre outras perspectivas de educação inclusiva.

Assim, no documento PNEEPEI (BRASIL, 2008a) indica-se a intenção de reestruturar a Educação Especial "na” perspectiva da Educação Inclusiva que se opóe à educação especializada substitutiva ao ensino regular: a perspectiva da Inclusão Total (full inclusion). Esta restruturação consolida-se com o Decreto no 6.571 de 2008 (BRASIL, 2008b) e com a Resolução no 4 de 2009 (BRASIL, 2009a), pois, dentre outros elementos, ambos definiram o Atendimento Educacional Especializado (AEE) como serviço não substitutivo ao ensino regular.

Subsequentemente, as Diretrizes Curriculares Nacionais Gerais para a Educação Básica (BRASIL, 2010b) também estabeleceram que os sistemas de ensino devem matricular os estudantes público-alvo da Educação Especial nas classes comuns do ensino regular e no AEE. E, outros documentos, como os dez volumes da coleção intitulada "A Educação Especial na perspectiva da Inclusão Escolar" e/ou as inúmeras notas técnicas publicadas Secretaria de Educação Especial (SEESP) e ou pela da Secretaria de Educação Continuada, Alfabetização, Diversidade e Inclusão (SECADI), repetiram a intenção de romper com o tradicional modelo de Educação Especial redesenhando-a "na” perspectiva da Educação Inclusiva.

Desta forma, mesmo em 2011 quando o Decreto no 7.611 (BRASIL, 2011a) revogou o Decreto no 6.571 de 2008 (BRASIL, 2008b), foram reiterados os princípios que rezam que é função do AEE complementar ou suplementar os serviços escolares, sem substituí-los. E, a partir da Lei no 12.796 de 2013 (BRASIL, 2013a), consolidaram-se novas interpretaçóes dos elementos da Educaçáo Especial na Lei nº 9.394 de 1996 (BRASIL, 1996).

Para Baptista (2011), a ênfase no contexto escolar comum dada por estes documentos alterou o plano normativo da Educação Especial brasileira. Esta alteração provocou mudanças conceituais e estruturais na Educação Especial (PRIETO, 2010; BUENO, 2012; GARCIA, 2013) e analisá-las é fundamental para a adequada atuação no campo em questão e para a adoção de um posicionamento crítico perante as proposiçóes e a retórica a elas associadas.

Ora, é necessário atentar para o fato de que os documentos oficiais têm sido utilizados para a colonização do vocabulário, do discurso e do pensamento educacional (SHIROMA; CAMPOS; GARCIA, 2005). Ou seja, frequentemente os documentos oficiais disseminam afirmações que pretendem oferecer representaçôes únicas sobre os fenômenos; que não apenas prescrevem as orientaçóes a serem adotadas, como também produzem a legitimação destas orientaçóes; e, que efetuam bricolagem de conceitos - usam conceitos antigos dando aos mesmos "ares de inovação" para fazer "velhas práticas" parecerem inovaçóes (idem).

Neste contexto, apesar dos conhecidos avanços quantitativos no que se refere à inserção na rede regular de ensino dos alunos atualmente demarcados como público-alvo da Educação Especial, perante os usos dados aos documentos oficiais e a diversidade de documentos que tem forjado restruturaçóes na Educação Especial, tornam-se explícitas duas questóes primordiais, a saber: que elementos constituem e como se configura a atual estrutura 
organizacional e conceitual da Educação Especial na perspectiva da Educação Inclusiva? Os elementos que foram alterados na estrutura em questão são permeados por novas práticas e/ou são apenas uma "roupagem" nova para tradicionais práticas?

Hipotetiza-se que a atual estrutura organizacional e educacional da Educação Especial, apesar de apresentar aparentes avanços em relação às estruturas que a precederam ${ }^{4}$, perpetua características e/ou contradições bastante semelhantes às identificadas nas mesmas. Bem como, delineia-se a presente pesquisa com o objetivo desvelar e analisar a estrutura organizacional e conceitual da Educação Especial brasileira, configurada nos documentos que orientam as políticas públicas relacionadas com esta modalidade de ensino e que foram publicados entre janeiro de 2008 e abril de 2013.

\section{Método}

Em uma abordagem qualitativa, nesta pesquisa documental, empregaram-se técnicas da análise categorial temática, descritas por Bardin (2008), a saber:

\begin{tabular}{|l|l|}
\hline Fase & \multicolumn{1}{|c|}{ Procedimentos } \\
\hline I & $\begin{array}{l}\text { Leitura e compilação de todos os documentos disponibilizadas no portal do Ministério da } \\
\text { Educação, nas abas da SEESP e da SECADI, no período de coleta (maio de 2013). }\end{array}$ \\
\hline II & $\begin{array}{l}\text { Identificação, nos documentos compilados na fase I, de frases/trechos que apresentam os } \\
\text { recursos humanos ou materiais e o modus operandi da estrutura organizacional da Educação } \\
\text { Especial. }\end{array}$ \\
\hline III & $\begin{array}{l}\text { As frases identificadas na fase anterior foram codificadas (atribui-se um código), recortadas } \\
\text { do documento original, referenciadas e classificadas em categorias e subcategorias, mediante } \\
\text { agrupamento em uma mesma categoria de todas as que versam sobre a mesma temática. }\end{array}$ \\
\hline IV & $\begin{array}{l}\text { Nomeação de cada categoria constituída pelo agrupamento de frases. Comparação dos ele- } \\
\text { mentos constituintes de cada uma das categorias com elementos equivalentes a eles em outros } \\
\text { momentos (antecedentes ao atual) das políticas de Educação Especial. }\end{array}$ \\
\hline
\end{tabular}

Quadro 1 - Procedimentos de coleta e análise dos dados.

$\mathrm{Na}$ Fase I, foram compilados todos os documentos que atendem aos seguintes critérios: a) ser documento elucidativo da política de educação especial na perspectiva inclusiva e/ou alterar conceitos e serviços da Educação Especial; b) não se constituir em parecer ou nota técnica sobre projeto de lei ou em projeto de lei ou plano nacional não aprovado; c) ter sido publicado entre janeiro de 2008 e abril de 2013; d) não se constituir em documento revogado entre 2008 e 2013 ou em republicação de um mesmo documento. Na fase IV sistematizaram-se os resultados conforme expresso nos tópicos subsequentes.

\footnotetext{
${ }^{4}$ As estruturas configuradas a partir da Política Nacional de Educação Especial (BRASIL,1994) e das Diretrizes Nacionais para a Educação Especial na Educação Básica (BRASIL, 2001) sãos exemplos precedentes a atual.
} 


\section{Resultados E Discussốes}

Dentre 83 documentos identificados no portal do Ministério de Educação no período de coleta, considerando os critérios supracitados, foram compilados e analisados 30 documentos:

\begin{tabular}{|c|c|}
\hline Indicativo da referência e fonte & Descriçáo de Conteúdo \\
\hline $\begin{array}{l}\text { Brasil (2009a); Brasil (2011a); Brasil (2012a); Brasil (2012b); } \\
\text { Brasil (2012c); Brasil (2013a); }\end{array}$ & $\begin{array}{l}\text { Leis que alteraram a estrutura organizacional } \\
\text { da educação especial. }\end{array}$ \\
\hline $\begin{array}{l}\text { Brasil (2008c); Brasil (2009b); Brasil (2010c); Brasil (2010d); } \\
\text { Brasil (2010e); Brasil (2010f); Brasil (2011b); Brasil (2011c); } \\
\text { Brasil (2011d); Brasil (2011e); Brasil (2011f); Brasil (2013b). }\end{array}$ & $\begin{array}{l}\text { Notas técnicas emitidas para orientar o } \\
\text { funcionamento da Educaçáo Especial. }\end{array}$ \\
\hline $\begin{array}{l}\text { Brasil (2008a); Brasil (2012d); Ropoli et al. (2010, v.1); Gomes, } \\
\text { Poulin e Figueiredo (2010, v.2);Domingues et al. (2010, v.3); } \\
\text { Alvez, Ferreira e Damázio (2010, v.4); Bosco, Mesquista e Maia } \\
\text { (2010, v.5); Sartoretto e Bersch (2010, v.6); Giacomini Sartoretto } \\
\text { e Bersch (2010, v.7); Melo e Pupo (2010, v.8); Delpretto, Giffoni } \\
\text { e Zardo (2010, v.9);Belisário Filho e Cunha (2010, v.10). }\end{array}$ & $\begin{array}{l}\text { Manuais orientadores de práticas e serviços } \\
\text { da Educação Especial na perspectiva da } \\
\text { educaçáo Inclusiva. Volumes da coleção a } \\
\text { Educação especial na perspectiva da Inclusão } \\
\text { Escolar. }\end{array}$ \\
\hline
\end{tabular}

Quadro 2 - corpus da pesquisa - documentos compilados.

A análise dos documentos compilados, orientada pelos objetivos desta pesquisa, possibilitou a constituição das seguintes categorias e subcategorias:

\begin{tabular}{|l|l|}
\hline \multicolumn{1}{|c|}{ Categorias } & \multicolumn{1}{c|}{ Subcategorias } \\
\hline $\begin{array}{l}\text { Recursos Humanos: pessoas direta- } \\
\text { mente envolvidas com a Educação } \\
\text { Especial. }\end{array}$ & $\begin{array}{l}\text { Público-alvo: conjunto de segmentos que é o destinatário das políticas de } \\
\text { Educaçáo Especial. } \\
\text { Profissionais: delimitaçóes dos profissionais da Educação Especial. }\end{array}$ \\
\hline $\begin{array}{l}\text { Recursos Materiais: indicaçóes dos } \\
\text { recursos materiais associados com a } \\
\text { Educação Especial. }\end{array}$ & $\begin{array}{l}\text { Lócus: Espaços associados com o AEE. } \\
\text { Recursos pedagógicos acessiveis: recursos de promoção da acessibilidade. } \\
\text { Financiamento: origens e critérios para a distribuição dos recursos finan- } \\
\text { ceiros para educação especial. }\end{array}$ \\
\hline $\begin{array}{l}\text { Modus operandi: formas adminis- } \\
\text { trativas e pedagógicas de desenvol- } \\
\text { vimento das práticas de Educação } \\
\text { Especial. }\end{array}$ & $\begin{array}{l}\text { Gestão: órgãos envolvidos com a gerência das políticas de Educação Espe- } \\
\text { cial e suas respectivas funçôes. } \\
\text { Práticas: orientaçôes sobre o desenvolvimento das práticas de Educação } \\
\text { Especial. }\end{array}$ \\
\hline
\end{tabular}

Quadro 3 - Categorias e subcategorias.

Os resultados associados a cada uma das categorias e subcategorias identificadas constituem o conteúdo dos tópicos subsequentes do presente artigo.

\subsection{Recursos humanos}

\subsubsection{Público-alvo da educaÇáo esPecial}

Em 2001 a indicação do público-alvo da Educação Especial era dada em termos da categoria necessidades educacionais especiais. Neste contexto, as Diretrizes Curriculares 
Nacionais para Educação Especial (BRASIL, 2001) expressavam que, tradicionalmente, a Educação Especial havia sido concebida como destinada apenas para "alunos que apresentam deficiências (mental, visual, física/motora e múltiplas); condutas típicas de síndrome e quadros psicológicos, neurológicos ou psiquiátricos, bem como de alunos que apresentam altas habilidades/superdotação" (BRASIL, 2001, p.45). Por isso, tais diretrizes propunham a adoção da categoria necessidades educacionais especiais (NEE) a partir da qual afirmavam assumir compromisso com a inclusão de uma gama mais ampla de pessoas.

No entanto, entre 2008 e 2013, todos os documentos oficiais relacionados com a Educação Especial e emitidos pelo Governo Federal, abandonaram a categoria NEE e restringiram o público-alvo da Educação Especial à tríade de segmentos que historicamente o compôs, a saber: pessoas com deficiência, com altas habilidades ou Superdotação ou com Transtornos Globais do Desenvolvimento. Como destaca Garcia (2013), neste contexto, o público-alvo da Educação Especial voltou a ser o que era contemplando anteriormente ao uso da categoria NEE. Não obstante, nos documentos analisados nesta pesquisa não encontram-se argumentações para justificar a mudança em questão.

Essa carência de explicaçóes incita questóes sem respostas oficiais, a saber: porque a categoria NEE não seria mais válida? Porque ela foi substituída? O que a mudança desta categoria implica em termos práticos? Que racionalidades sustentam as atuais formas de nomear e identificar os alunos demarcados como público-alvo da Educação Especial? Existiria uma relação entre o fracasso das políticas anteriores e a categoria NEE?

Conforme Carvalho (2013), ao que parece, a esta mudança no público-alvo da Educação Especial está associada à demarcação de um conjunto de segmentos mais específicos, identificável por diagnósticos clínicos, centrados em suas condiçóes orgânicas e/ou comportamentais. Talvez por isso, da primeira versão do documento denominado PNEEPEI (BRASIL, 2008a) para a segunda versão do mesmo publicada no compêndio "Marcos políticos-legais da Educação Especial na Perspectiva da Educação Inclusiva” (BRASIL, 2010a), transtornos que eram mencionados como "dislexia, disortografia, disgrafia, discalculia, transtorno de atenção e hiperatividade" (BRASIL, 2008a, p.13) passaram a não ser citados e a ausência de alusóes aos mesmos, repetiu-se em todos os demais documentos analisados nesta pesquisa.

Assim, com a supressão da categoria necessidades educacionais especiais, certos grupos deixaram ser entendidos como público-alvo da Educação Especial e é necessário perguntar-se quem se beneficiou com essa restrição. Aliás, com a definição do público-alvo da Educação Especial estão implicadas as estatísticas escolares; a organização e funcionamento do AEE e a própria delimitação dos profissionais da Educação Especial. Por isso, pergunta-se: quais são os profissionais associados com o AEE dos alunos público-alvo da Educação Especial?

\subsubsection{Profissionais da Educaçáo Especial}

No transcorrer dos documentos analisados nesta pesquisa os seguintes profissionais são associados com o atendimento educacional dos alunos público-alvo da Educação Especial: professores de AEE; professores do ensino regular capacitados para a integração desses educandos nas classes comuns; profissional para atuar em atividades de apoio; professor auxiliar; profissional tradutor e intérprete de Libras e guia-intérprete. 
Este conjunto de profissionais difere em relação ao conjunto de profissionais que foram associados às políticas de Educação Especial anteriores a atual, mais em relação a gama e o perfil das atividades e conhecimentos a que eles estão incumbidos pelos documentos oficiais, do que em relação a sua variabilidade. Aliás, é preciso lembrar que estes profissionais, em políticas educacionais precedentes a atual, geralmente atuavam e eram formados para atuação com apenas um segmento de sujeitos público-alvo da Educação Especial e agora passaram a atuar com sujeitos de todos os segmentos associados com esta modalidade de ensino.

Assim estabeleceu-se que o AEE deve ser realizado mediante a atuação de profissionais com conhecimentos específicos em ensino da Língua Brasileira de Sinais; do sistema Braille, do Soroban, da orientação e mobilidade, das atividades de vida autônoma e da comunicação alternativa; do desenvolvimento dos processos mentais superiores; dos programas de enriquecimento curricular; da adequação e produção de materiais didáticos; da utilização de recursos ópticos e não ópticos; e, da tecnologia assistiva, dentre outros (BRASIL, 2008a).

Neste contexto, a Resolução no 04, de 02 de outubro de 2009 (BRASIL, 2009a) determinou que os professores de AEE têm atribuiçóes como identificar, elaborar, produzir e organizar serviços, recursos pedagógicos, de acessibilidade e estratégias considerando as necessidades específicas dos alunos público-alvo da Educação Especial; elaborar e executar plano de AEE, avaliando a funcionalidade e a aplicabilidade dos recursos pedagógicos e de acessibilidade; e, ensinar e usar a tecnologia assistiva. Emitida pela SEESP em 2010, a Nota Técnica no 11 (BRASIL, 2010c), a estas atribuiçóes acrescenta a de desenvolver atividades como o ensino de Libras; ensino da Língua Portuguesa escrita para alunos com surdez; de Comunicação Aumentativa e Alternativa; do sistema Braille, do uso do soroban e das técnicas para a orientação e mobilidade para alunos cegos; do uso dos recursos de Tecnologia Assistiva; e, de atividades de vida autônoma e social. Trata-se, portanto, como indica Garcia (2013), de um profissional tão multifuncional o quanto os espaços em eles devem atuar.

Para desempenhar estas múltiplas funções os documentos oficiais (BRASIL, 2008a, 2009a, 2011a) estabelecem que o professor de Educação Especial, deve ter como base da sua formação inicial e continuada, conhecimentos gerais para o exercício da docência e conhecimentos específicos da área. Também estabelecem que os sistemas de ensino devem assegurar ao públicoalvo da Educação Especial, "professores com especialização adequada em nível médio ou superior, para atendimento especializado, bem como professores do ensino regular capacitados para a integração desses educandos nas classes comuns" (BRASIL, 2013a, art. 59).

Além dos cursos de especialização, em inúmeros documentos analisados nesta pesquisa (BRASIL, 2008c, 2011b, 2011d) são citadas experiências e propostas com a formação continuada de professores para Educação Especial, tais como as ofertadas por meio da Universidade Aberta do Brasil e da Plataforma Paulo Freire. De qualquer forma, perpetuase a condição em que pessoas com formação de nível médio e/ou com uma licenciatura qualquer combinada com uma especialização (lato sensu) sejam os polivalentes profissionais que desenvolvam o multifuncional serviço das SRM.

Ressalta-se que os cursos lato sensu em Educação Especial e as propostas de formação continuada de professores não são submetidos a avaliaçôes similares às dos cursos de graduação e de pós-graduação stricto sensu; que em grande parte do país estes cursos não apresentam 
períodos de estágio obrigatório; e, que, geralmente, os cursos lato sensu têm carga horária reduzida (360 horas). Por isso, pergunta-se: esta condição formativa é suficiente para preparar professores para o AEE dos segmentos que compóe o público-alvo da Educação Especial e/ou para possibilitar a reflexão teórica e política sobre as práticas pedagógicas relacionadas com esta modalidade de ensino?

Quanto ao profissional tradutor e intérprete de Libras os documentos oficiais (BRASIL, 2008a, 2011d) destacam a inclusão de uma disciplina voltada ao ensino dessa língua, nos currículos dos cursos de formação de professores; a formação e a certificação dos profissionais envolvidos nos processos escolares de surdos (professores, instrutores e tradutores/ intérpretes). Bem como, citam as propostas governamentais para minimizar a histórica carência de professores de Libras, como programas de formação de professores em Letras/ Libras promovidos pela Universidade Aberta do Brasil; e, o curso de Pedagogia Bilíngue Libras/ Língua Portuguesa do Instituto Nacional de Educação de Surdos.

Por sua vez, no que se refere ao profissional para atuar em atividades de apoio no contexto da educação dos segmentos público-alvo da Educação Especial, ressalta-se que, a demanda pelo mesmo é justificada quando a necessidade específica do estudante público-alvo da educação especial não for atendida no contexto geral disponibilizado aos demais estudantes (BRASIL, 2010e). Bem como destaca-se que "não é atribuição do profissional de apoio desenvolver atividades educacionais diferenciadas, ao aluno público-alvo da educação especial, e nem responsabilizar-se pelo ensino deste aluno" (BRASIL, 2010e)

Destarte, na atual política frisa-se que os profissionais de apoio às atividades de locomoção, higiene, alimentação, prestam auxílio individualizado aos estudantes que não realizam essas atividades com independência, e que "esse apoio ocorre conforme as especificidades apresentadas pelo estudante, relacionadas à sua condição de funcionalidade e não à condição de deficiência” (BRASIL, 2010e). Destaca-se também que outros documentos (BRASIL, 2012a, 2013 b), asseguram profissionais de apoio para estudantes com transtorno do espectro autista, desde que comprovada sua necessidade. No entanto, apesar de mencionada essas atribuiçóes destes profissionais, nos documentos analisados nesta pesquisa não há orientação quanto à formação que os mesmos devem ter.

Assim, em relação ao conjunto de profissionais associados com a estrutura de atendimento educacional dos alunos público-alvo da Educação Especial, delineia-se um quadro em que são vislumbráveis situações como profissionais de apoio com características formativas não delineadas; e, professores de AEE com funçóes amplificadas e reconfiguradas, dos quais se exige formaçóes menos específicas e mais restritas do que as que eram exigidas nos momentos históricos em que ofertava-se amplamente cursos de graduação com habilitação específica para atuação com segmentos público-alvo da Educação Especial.

\subsection{RECURSOS MATERIAIS}

\subsubsection{LóCus da EduCaÇÃo ESPECIAL}

Como espaços associados com a Educação Especial, nos diversos documentos analisados nesta pesquisa, são citados os seguintes: salas de recursos multifuncionais (SRM); 
centros de AEE da rede pública ou de instituiçôes comunitárias, confessionais ou filantrópicas sem fins lucrativos; centros de apoio pedagógico à educação de surdos; ambientes domiciliares; ambientes hospitalares; os núcleos de atividades para altas habilidades; e, os núcleos de acessibilidade das instituiçóes federais de educação superior.

Contrariando os princípios da perspectiva de educação inclusiva que atualmente orienta as políticas de Educação Especial, a Lei de Diretrizes e Bases da Educação Nacional ainda expressa que AEE "será feito em classes, escolas ou serviços especializados, sempre que, em função das condições específicas dos alunos, não for possível a sua integração nas classes comuns de ensino regular" (BRASIL, 2013a). Assim, contraditoriamente perpetua-se a possibilidade de que para alguns alunos, a Educação Especial possa ser realizada em ambientes segregados. Além disso, o Decreto presidencial no 7.611 de 2011 (BRASIL, 2011a,) também aponta para a perpetuação das classes especiais, uma vez que destaca que estas serão consideradas no levantamento das matrículas em Educação Especial.

De qualquer forma, em diversos documentos (BRASIL, 2008a, 2008c, 2010a, 2011a, 2012b) analisados nesta pesquisa dentre os espaços associados com a Educação Especial na política educacional contemporânea, as SRM são apresentadas como lócus prioritário do AEE. As SRM já eram previstas em termos de salas de recursos desde a década de 80 do século passado. Mazzota (1982) já ressaltava que as mesmas eram espaços das escolas regulares providos com materiais especiais, nos quais professores especializados deveriam auxiliar os alunos público-alvo da Educação Especial naqueles aspectos específicos em que precisam de ajuda para se manter na classe comum.

No entanto, a partir do Programa de Implantação de Salas de Recursos Multifuncionais do Ministério da Educação, reconfigurou-se o sistema misto [atendimento domiciliar, classe comum, classe especial, classe hospitalar, ensino com professor itinerante, escola especial, oficina pedagógica, sala de estimulação essencial, sala de recursos], integrado por escolas comuns e especiais (CARVALHO, 2013). Centralizou-se a Educação Especial nas SRM definidas como "ambientes dotados de equipamentos, mobiliários e materiais didáticos e pedagógicos para a oferta do AEE” (BRASIL, 2011a). Como esta definição expressa e como indica a própria expressão salas de recursos multifuncionais (não trata-se de uma sala de aula), a ênfase educativa destes espaços observada por Mazzotta (1982), na atual política foi substituída por uma ênfase em recursos multifuncionais.

Com esta nova definição atribuída à expressão SRM foram publicados documentos oficiais (BRASIL, 2012b, 2012d) com orientaçôes para a institucionalização nas escolas de dois tipos de SRM, a saber: tipo 1 - dotada de equipamentos voltados para o atendimento de todos os segmentos de alunos público-alvo da Educação Especial; tipo II, dotada dos mesmos recursos das salas tipo I, acrescidos de recursos específicos para estudantes com deficiência visual. Estes dois tipos de SRM devem atender estudantes de qualquer um dos segmentos público-alvo da Educação Especial matriculados no Ensino Regular ou em cursos de Educação de Jovens e Adultos, pois nestas duas situaçóes os mesmos tem direito à matricula no AEE em SRM ou em centro de AEE (BRASIL, 2011c).

Neste contexto, concorda-se com Bueno (2012) quanto à interpretação de que a restrição do AEE às SRM, espaço especificamente voltado para o público-alvo da Educação 
Especial, que conta com recursos e profissionais específicos para este público, pode indicar a permanência da perspectiva tradicional da Educação Especial, pois as SRM preservam a antinomia entre ensino regular e Educação Especial.

Por sua vez, os centros de AEE (públicos ou privados sem fins lucrativos) são apresentados nos documentos oficiais (BRASIL, 2011a, 2010f) como espaços que devem cumprir as exigências legais estabelecidas pelo Conselho de Educação do respectivo sistema de ensino, quanto ao seu credenciamento, autorização de funcionamento e organização. Outros documentos (BRASIL, 2010b, 2010d) destacam que estes centros devem realizar oferta do AEE, de forma não substitutiva à escolarização dos alunos público-alvo da educação especial; organizar e disponibilizar recursos e serviços pedagógicos e de acessibilidade para atendimento às necessidades educacionais específicas destes alunos; e, atuar em interface com as escolas regulares, promovendo os apoios para participação e aprendizagem dos alunos nas classes comuns.

Quanto aos núcleos de acessibilidade das instituições federais de educação superior, a atual política estabelece que os mesmos são espaços que "[...] visam eliminar barreiras físicas, de comunicação e de informação que restringem a participação e o desenvolvimento acadêmico e social de estudantes com deficiência” (BRASIL, 2011a). No que concerne às orientaçóes para a Educação Especial em ambientes domiciliares e hospitalares e em núcleos de atividades para altas habilidades/superdotação, existem poucos esclarecimentos nos documentos analisados nesta pesquisa. Estabelece-se apenas que em casos de AEE “em ambiente hospitalar ou domiciliar, será ofertada aos alunos, pelo respectivo sistema de ensino, a Educação Especial de forma complementar ou suplementar" (BRASIL, 2009a).

Neste contexto, o Instituto Nacional de Educação de Surdos e o Instituto Benjamim Constant, instituições de importância histórica para o nascimento da Educação Especial no Brasil, são apontadas nos documentos analisados (BRASIL, 2011e, 2011f, 2012c) como instituições que devem ter papel ressignificado. Os mesmos documentos determinam que na atual política estes institutos devem atuar como centros de referência nacional nas áreas de pesquisa e formação de educadores, produção de materiais didáticos acessíveis voltados para pessoas com surdez e pessoas com deficiência visual.

Perante o retrato delineado quanto aos espaços da atual Educação Especial, cabe perguntar por que as SRM, ambientes distintos das salas de aulas regulares, são o lócus preferencial da Educação Especial? Porque os recursos e serviços que as SRM ofertam não estão nas salas de aulas regulares reconfigurando práticas historicamente desenvolvidas para um padrão inexistente de homogêneos alunos? Porque, um espaço diferenciado contando com recursos, profissionais e propostas típicas da Educação Especial, é considerado algo tão inovador e importante na atual política? Qual a intenção da concentração dos serviços de Educação Especial nestes espaços? São perguntas para as quais não há respostas oficiais, mas que podem ter relaçôes com o financiamento do AEE. 


\subsubsection{Financiamento do AEE}

O financiamento da Educação Especial brasileira historicamente esteve associado com o repasse de verbas para a iniciativa privada (MAZZOTTA, 1982). O repasse de verbas para a iniciativa privada ainda é possível na atual estrutura organizacional da Educação Especial, no entanto o financiamento da matrícula no AEE é condicionado à matrícula no ensino regular da rede pública (BRASIL, 2009a, 2009b), o que implica cômputo do estudante tanto na educação regular da rede pública, quanto no AEE. A Nota técnica n 62 emitida pela SECADI (BRASIL, 2011 b) indica que o apoio financeiro às instituiçóes especializadas destina-se, especialmente, àquelas pessoas que se encontram fora da faixa etária de escolarização obrigatória, em razão de um processo histórico de exclusão escolar. E, Portaria no 25, de 19 de junho de 2012 (BRASIL, 2012b) determina que as instituições de ensino interessadas em aderir ao Programa de Implantação das SRM “devem ser, obrigatoriamente, públicas, com matrícula de estudante público-alvo da educação especial em classe comum”.

Desta forma, estabelece-se que, dentre outras responsabilidades, cabe a Uniāo prestar apoio técnico e financeiro para o aprimoramento do AEE; para implantação de SRM; para a formação continuada de professores; para o desenvolvimento da educação bilíngue para estudantes surdos ou com deficiência auditiva e do ensino do Braile para estudantes com deficiência visual; para a educação na perspectiva da educação inclusiva; para adequação arquitetônica de prédios escolares para acessibilidade; e, para elaboração e distribuição de recursos educacionais para a acessibilidade (BRASIL, 2011a).

Em síntese, tem-se que a política pública de financiamento da Educação Especial na perspectiva da Educação Inclusiva estabelece: a contabilização da matrícula do AEE no âmbito do Fundo de Manutenção e Desenvolvimento da Educação Básica e de Valorização dos Profissionais da Educação, sem prejuízo da matrícula no ensino regular; a destinação anual de recursos do Programa Dinheiro Direto na Escola, às escolas públicas e privadas sem fins lucrativos, que ofertem educação especial; e a destinação de recursos do Programa Nacional da Alimentação Escolar para o atendimento de estudantes matriculados nos Centros de AEE e registrados no censo Escolar do Ministério da Cultura (BRASIL, 2011b).

Desta forma, mesmo com a perpetuação da possibilidade de repasse de verba pública para as instituiçóes privadas que ofertam Educação Especial, entende-se que a obrigatoriedade da matrícula na rede pública concomitante à matricula no AEE representa um avanço no que se refere ao financiamento da educação especial pública, pois gera no âmbito da escola regular investimentos em recursos(temática do próximo tópico) que facilitam o acesso dos segmentos público-alvo da Educação Especial, ao espaço da escola pública.

\subsubsection{ReCURSOS PEDAGógicos ACESSÍveIS}

Na política de Educação Especial na perspectiva da educação inclusiva, foram postos em destaque os recursos pedagógicos acessíveis: "aqueles que asseguram condiçôes de acesso ao currículo dos alunos com deficiência ou mobilidade reduzida, promovendo a utilização dos materiais didáticos e pedagógicos, dos espaços, dos mobiliários e equipamentos, dos sistemas de comunicação e informação, dos transportes e dos demais serviçoo" (BRASIL, 2009a). 
Além de estarem previstos na Resolução no 04, de 02 de outubro de 2009 (BRASIL, 2009a) e no decreto presidencial 7.611 de 2011 (BRASIL, 2011a), de constarem na própria definição de AEE, de serem descritos nos manuais orientadores da política, os recursos pedagógicos acessíveis receberam destaque nos manuais elaborados para a formação de professores para atuação com Educação Especial, tais como os volumes da coleção "A Educação Especial na Perspectiva da Inclusão Escolar”.

Por exemplo, Sartoretto e Bersch (2010) versam exclusivamente sobre recursos de acessibilidade e assim centram-se em orientar os professores na seleção, confecção e indicação de recursos pedagógicos acessíveis, de baixa e alta tecnologia (acessíveis ou inacessíveis às escolas brasileiras). Como Sartoretto e Bersch (2010), Melo e Pupo (2010) também enfocam recursos materiais, apresentando informaçóes sobre livros acessíveis e recursos para tornar a informática acessível para pessoas com distintas deficiências.

Giacomini, Sartoretto e Bersch (2010), apresentam recursos de adequação postural e mobilidade, como cadeiras e mobiliário e outros voltados para a acessibilidade espacial, com especial ênfase para os recursos demandados por pessoas com deficiência física ou visual, ou surdocegueira. Domingues et al. (2010) apresentam recursos de acessibilidade para os alunos com baixa visão e recursos de tecnologia de informação e comunicação. Ropoli et al. (2010) e Bosco, Mesquita e Maia (2010) abordam materiais didáticos adaptados, bem como recursos de tecnologia assistiva para pessoas com deficiência.

Neste contexto, acredita-se que a ênfase dada a estes recursos aponta para propostas de AEE direcionadas prioritariamente para a gerência, elaboração, adaptação de recursos pedagógicos acessíveis e para o preparo dos alunos para o uso destes mesmos recursos. $\mathrm{O}$ direcionamento do AEE para estas propostas em detrimento da dimensão pedagógica deste serviço parece ser, portanto, parte do modus operandi da atual política.

\subsection{Modus OPERANDI}

Nos documentos analisados nesta pesquisa observa-se que a perspectiva de Educação Inclusiva denominada Inclusão Total, é um fundamento do modus operandi da atual Educação Especial brasileira. Percebe-se esta perspectiva tanto em indicações de que "os encaminhamentos dos alunos às classes e escolas especiais sejam eliminados por completo e com urgência” (ROPOLI, 2010, p.9) quanto quando, por exemplo, a Lei 12.764, de 27 de dezembro de 2012 (BRASIL, 2012a) torna crime passível de punição, a negação da matrícula dos alunos com Transtornos Globais do Desenvolvimento na escola regular.

Neste contexto, em diversos documentos analisados (BRASIL, 2008a, 2008b, 2010c, 2010d, 2010f, 2011c, 2011d; ROPOLI, 2010), as críticas às práticas típicas da educação realizada em instituiçóes especializadas substitutivas do ensino regular são tão presentes que constituem outro fundamento delineador do funcionamento atual estrutura organizacional da Educação Especial. Trata-se de contraposiçóes ao ensino individualizado para alunos público-alvo da Educação Especial; a possibilidade de agrupar alunos considerando uma de suas características "especiais" (por exemplo, a deficiência); a currículos adaptados/adaptaçóes curriculares; a métodos especiais para pessoas com deficiência; ao encaminhamentos dos alunos às classes e escolas especiais; e, ao modelo clínico de Educação Especial. 
Destes argumentos e contraposições sustenta-se que a educação inclusiva demanda a constituição de um "sistema educacional inclusivo" (BRASIL, 2009b) em que a Educação Especial tenha um "novo" modus operandi. Este novo modus operandié delineado nos documentos analisados nesta pesquisa com (re) estruturações na esfera administrativa da Educação Especial e nas formas de oferta e prática do AEE.

Assim, a partir do Decreto no 7.690, de 2 de março de 2012 (BRASIL, 2012c) a administração da Educação Especial brasileira efetua-se a partir de diretorias da Secretaria de Educação Continuada, Alfabetização, Diversidade e Inclusão, enquanto anteriormente efetuava-se a partir de secretaria própria (SEESP). Este reposicionamento da gestão da Educação Especial para "dentro" de uma secretaria que agrega outras várias diretorias voltadas para outros segmentos com especificidades, parece articular-se com a lógica de tornar a Educação Especial uma modalidade não paralela de ensino.

Neste meandro, a Educação Especial consolidou-se como modalidade transversal de ensino que "perpassa" todos os níveis e modalidades de ensino ofertando recursos e serviços denominados como AEE (BRASIL, 2008a). E, o Decreto 7.611 de 2011 (BRASIL, 2011a) definiu como objetivos do AEE a promoção condiçóes de acesso, participação e aprendizagem no ensino regular; a garantia serviços de apoio especializados de acordo com as necessidades individuais dos estudantes; o fomento desenvolvimento de recursos didáticos e pedagógicos que eliminem as barreiras no processo de ensino e aprendizagem; e a criação condiçóes para a continuidade de estudos nos demais níveis e etapas de ensino.

Com estes objetivos, o modus operandi a ser adotado para o desenvolvimento do AEE é caracterizado/orientado pelo Ministério de Educação, nos dez volumes da coleção "A Educação Especial na Perspectiva da Inclusão Escolar”. Nestes volumes, predominantemente em um tom prescritivo, com superficialidade de conteúdos teóricos e apresentação no estilo cartilha, a estruturação dos serviços de Educação Especial é descrita como um processo que deveria ser principiado por estudos de caso e seguiria com a aplicação de planos de AEE.

Assim, no primeiro volume da coleção em questão, Ropoli et al. (2010) apresenta roteiros para o desenvolvimento dos estudos de casos e para o desenvolvimento de planos (individualizados) de AEE. Em outros volumes, como os produzidos por Gomes, Poulin e Figueiredo (2010), Domingues et al. (2010) e Alvez, Ferreira e Damázio (2010), seguindo os roteiros apresentados por Ropoli et al. (2010), apresentam exemplos de estudos de caso e de planos de AEE. Os demais volumes enfocam aspectos clínicos do público-alvo da Educação Especial e recursos pedagógicos acessíveis.

Por exemplo, em Belisário Fillho e Cunha (2010) constam repetitivas descrições de elementos associados com o diagnóstico de Transtornos Globais de Desenvolvimento, bem como constam críticas a metodologias do campo terapêutico relacionadas com sugestóes de práticas oriundas deste mesmo campo. No entanto, em Filho e Cunha (2010) praticamente não constam orientaçóes e análises sobre o fazer pedagógico junto ao segmento em questão.

Em Giacomini, Sartoretto e Bersch (2010), constam orientaçóes para a correção da retroversão pélvica e da cifose toráxica, debates sobre reflexos humanos (reflexo tônico cervical assimétrico, simétrico e labiríntico); exemplos de recursos de adequação de mobilidade e noções 
de acessibilidade. E, em Delpretto, Giffoni e Zardo (2010) constam debates sobre a teoria piagetiana, repetitivas exposiçóes retratando o funcionamento neurológico do ser humano e paralelos entre estruturas cerebrais normais e atípicas.

Além desses aspectos, para outros grupos, como para as pessoas com deficiência intelectual, com deficiência visual, com surdez ou surdocegueira, as orientaçóes expressas nos volumes da coleção em questão enfocam ora os aspectos avaliativos, ora as adequaçóes de recursos materiais e apenas em alguns casos o fazer pedagógico. Por exemplo, em Gomes, Poulin e Figueiredo (2010), a discussão sobre a educação das pessoas com deficiência intelectual é dada em termos de contraposiçóes a propostas pautadas em aprendizagens mecânicas, em repetição e memória e, principalmente, em exposiçóes sobre a avaliação das pessoas com deficiência intelectual nas salas de aula, na SRM e na família.

Já em Bosco, Mesquista e Maia (2010) constam discussóes específicas sobre adequaçóes de recursos visuais, auditivos e táteis, sobre posição e distância, movimentação de professor e aluno, e sobre recursos pedagógicos acessíveis no contexto da educação de pessoas com surdocegueira; e, em Domingues et al. (2010) e em Alvez, Ferreira e Damásio (2010), em um enfoque educativo raramente observado nos outros volumes da coleção em questão, apresenta-se, respectivamente, discussóes que caracterizam a formação de conceitos e a construção de conhecimentos e a aprendizagem e alfabetização de alunos com cegueira e a proposta da abordagem bilíngue para educação de pessoas com surdez, com ênfase AEE para o ensino em libras; para o ensino de libras; e, para o ensino da língua portuguesa.

Tem-se então que, nos volumes da coleção "A Educação Especial na Perspectiva da Inclusão Escolar", observa-se predominantemente a discussão sobre aspectos biológicos, clínicos dos segmentos que compóe o público-alvo da Educação Especial; sobre avaliação da educação das pessoas com deficiência; ou sobre o conhecimento técnico associado recursos pedagógicos acessíveis. Com estes enfoques, incita-se a perpetuação de velhos traços da Educação Especial, como o descrito por Bueno (2012), a saber: a realização de práticas pautadas em modelos prédefinidos, originários da Biologia e da Psicologia.

\section{Conclusóes}

A atual estrutura organizacional e conceitual da Educação Especial, apesar de apresentar aparentes avanços em relação às estruturas que a precederam, perpetua características e/ou contradiçóes bastante semelhantes às identificadas nas mesmas, a saber:

- Delimita o público-alvo da Educação Especial no conjunto de segmentos que tradicionalmente o compôs, negligenciando recursos para outros segmentos que poderiam demandar AEE;

- Restringe as exigências relacionadas com a formação dos professores de AEE, ao mesmo tempo em que amplifica as funçóes destes professores;

- Para o AEE, delimita um espaço (SRM) diferenciado do utilizado pelos alunos sem necessidades educacionais especiais, preservando a tradicional antinomia entre Educação Especial e Educação Regular; 
- Mantem o financiamento público dos serviços prestados por instituiçóes privadas; apresenta manuais orientadores do AEE com maior ênfase nos aspectos clínicos dos segmentos público-alvo da Educação Especial, do que em discussóes sobre processos de ensino;

- Contrapóe-se ao modelo clínico de Educação Especial e concomitantemente propóe propostas típicas do modelo clínico de Educação Especial, tais como: um espaço diferenciado para Educação Especial, com profissionais especializados, com práticas orientadas por manuais que enfatizam os aspectos clínicos do público-alvo da Educação Especial.

Perante estas conclusóes, sugerem-se revisões na estrutura organizacional e conceitual da Educação Especial pautadas em amplos processos dialógicos entre profissionais, pesquisadores, alunos e pais dos alunos público-alvo da modalidade de ensino em questão.

\section{REFERÊNCIAS}

ALVEZ, C.B.; FERREIRA, J.; DAMÁZIO, M. Abordagem bilíngue na escolarização de pessoas com surdez. Brasília, DF: MEC, 2010. v.4. (Coleção a Educação Especial na Perspectiva da Inclusão Escolar).

BAPTISTA, C. R. Ação pedagógica e educação especial: a sala de recursos como prioridade na oferta de serviços especializados. Revista Brasileira de Educaçâo Especial, Marília, v.17, n.spe1, p.59-76, 2011. Disponível em: <http:/www.scielo.br/scielo.php?pid=S1413-65382011000400006\&script=sci_ abstract\&tlng=pt>. Acesso em: 12 jan. 2013.

BARDIN, L. Análise de conteúdo. 19. ed. Lisboa: Ediçôes 70, 2008.

BELISÁRIO FILHO, J. F.; CUNHA, P. Transtornos globais do desenvolvimento. Brasília, DF: MEC, 2010. v.9. (Coleção a Educação Especial na Perspectiva da Inclusão Escolar).

BOSCO, I.C.M.G.; MESQUITA, S.; MAIA, S.R.. Surdocegueira e deficiência múltipla. Brasília, DF: MEC, 2010. v.5. (Coleção a Educação Especial na Perspectiva da Inclusão Escolar).

BRASIL. MEC. Política Nacional de Educação Especial. Brasília, DF: MEC, 1994. . Lei n. 9.394, de 20 de dezembro de 1996. Brasília, DF: 1996.

. MEC. CNE. Resolução no 2, de 11 de setembro de 2001. Brasília, DF: MEC, 2001.

. MEC. Política Nacional de Educação Especial na Perspectiva da Educação Inclusiva. Brasília, DF: MEC, 2008a.

. Decreto $n^{\circ}$ 6.571, de 17 de setembro de 2008. Brasília, DF: 2008b.

.MEC. Nota Técnica No 13. A educação especial e sua operacionalização pelos sistemas de ensino. Brasília, DF: MEC, 2008c.

. MEC. Resolução no. 4, de 2 de outubro de 2009. Brasília, DF: MEC, 2009a.

. MEC. Nota Técnica No 01. Esclarecimentos sobre a distribuição do recurso do FUNDEB para alunos do AEE. Brasília, DF: MEC, 2009b.

. MEC.SEESP. Marcos políticos-legais da Educação Especial na Perspectiva da Educação Inclusiva. SEESP. Brasília, DF: SEESP, 2010a.

. MEC. Resolução CNE/CEB no 4, de 13 de julho de 2010. Brasília, DF: MEC 2010b. 
BRASIL. MEC.SEESP. Nota Técnica No 11. Orientaçóes para a institucionalização na escola, da oferta do AEE em Salas de Recursos Multifuncionais. Brasília, DF: MEC, 2010c.

. MEC.SEESP. Nota Técnica No 15. Orientaçóes sobre atendimento educacional especializado na rede privada. Brasília, DF: MEC, 2010d.

. MEC.SEESP. Nota Técnica No 19. Profissionais de apoio para alunos com deficiência matriculados nas escolas comuns da rede públicas de ensino. Brasília, DF: 2010e.

. SEESP. Nota Técnica No 9. Orientaçóes para a organização de centros de atendimento educacional especializado. Brasília, DF: $2010 f$.

. MEC. Decreto no 7.611, de 17 de novembro de 2011. Brasília, DF: MEC, 2011a.

. MEC.SECADI. Nota técnica $n^{\circ}$ 62. Apresenta orientaçôes aos sistemas de ensino sobre o Decreto no 7.611 de 2011. Brasília, DF: MEC, 2011 b.

. MEC.SECADI. Nota Técnica No 03. Atendimento de estudantes público-alvo da educação especial com 18 anos ou mais. Brasília, DF: MEC, 2011c.

MEC, 2011d.

MEC.SECADI. Nota Técnica No 05. Implementação da educação bilíngue. Brasília, DF:

. MEC. Nota Técnica No 06. Avaliação de estudante com deficiência intelectual. Brasília, DF:

MEC, 2011e.

. MEC.SECADI. Nota Técnica No 07. INES e IBC. Brasília, DF: MEC, $2011 \mathrm{f}$.

. Lei 12.764, de 27 de dezembro de 2012. Brasília, DF: 2012a.

. Portaria no 25, de 19 de junho de 2012. Brasília, DF: MEC, 2012b.

. Decreto no 7.690, de 2 de março de 2012. Brasília, DF: MEC, 2012c.

. MEC. SECADI. Documento orientador da implementação das salas de recursos multifuncionais. Brasília, DF: MEC/SECADI, 2012d.

. Lei no 12.796, de 4 de abril de 2013. Brasília, DF: MEC, $2013 a$.

. MEC.SECADI. DPEE. Nota técnica n²4. Orientação aos sistemas de ensino para a implementação da Lei no 12.764-2012. Brasília, DF: MEC, 2013 b.

BUENO, J. G. S. As pesquisas e a produção do conhecimento em educação especial: as investigaçóes sobre políticas de educação especial no Brasil. Distúrbios da Comunicação, v.24, n.3, p. 285-297, 2012.

CARVALHO, E. N. S. Educação especial e inclusiva no ordenamento jurídico brasileiro. Revista Educação Especial, Rio de Janeiro, v.26, n.46, p.261-276, 2013. Disponível em: <http://www.ufsm.br/ revistaeducacaoespecial>. Acesso em: 18 jan. 2014.

DELPRETTO, B. M. L. Altas habilidades/superdotaçâo. Brasília, DF: MEC, 2010. v.10. (Coleção a Educação Especial na Perspectiva da Inclusão Escolar).

DOMINGUES, C. A. et.al. Os alunos com deficiência visual: baixa visão e cegueira. Brasília, DF: MEC, 2010. v.3. (Coleção a Educação Especial na Perspectiva da Inclusão Escolar).

GARCIA, R. M. C. Política de educação especial na perspectiva inclusiva e a formação docente no Brasil. Revista Brasileira de Educação, Rio de Janeiro, v.18, n.52, p.101-119, 2013. Disponível em: <http://www.scielo.br/pdf/rbedu/v18n52/07.pdf>. Acesso em: 10 dez. 2013. 
GIACOMINI, L.; SARTORETTO, M.L.; BERSCH, R. C. Orientação e mobilidade, adequação postural e acessibilidade espacial. Brasília, DF: MEC, 2010. v.7. (Coleção a Educação Especial na Perspectiva da Inclusão Escolar).

GOMES, A. L.; POULIN, J.; FIGUEIREDO, R.V. O atendimento educacional especializado para alunos com deficiência intelectual. Brasília, DF: MEC, 2010. v.2 (Coleção a Educação Especial na Perspectiva da Inclusão Escolar).

MAZZOTTA, M. J. S. Fundamentos da educação especial. São Paulo: Pioneira, 1982.

MELO, A. M.; PUPO, D.T. Livro acessivel e informática acessivel. Brasília, DF: MEC, 2010. v.8. (Coleção a Educação Especial na Perspectiva da Inclusão Escolar).

PRIETO, R. G. Políticas de inclusão escolar no Brasil: sobre novos/velhos significados para educação especial. In: MENDES, E. G.; ALMEIDA, M. A.(Org.). Das margens ao centro: perspectiva para as políticas e práticas educacionais no contexto da educação especial inclusiva. Araraquara: Junqueira \& Marin, 2010, p. 61-78.

ROPOLI, E.A. et al. A escola comum inclusiva. Brasília, DF: MEC, SEESP; Fortaleza: UFC, 2010. v.1. (Coleção a Educação Especial na Perspectiva da Inclusão Escolar).

SARTORETTO, M. L.; BERSCH, R. C. R. Recursos pedagógicos acessiveis e comunicação aumentativa e alternativa. Brasília, DF: MEC, 2010. v.6. (Coleção a Educação Especial na Perspectiva da Inclusão Escolar).

SHIROMA, E. O.; CAMPOS, R. F.; GARCIA, R. M. C. Decifrar textos para compreender a política. Perspectiva, Florianópolis, v.23, n.2, p.427-446, 2005.

Recebido em: 30/01/2014

Reformulado em: 20/09/2014

Aprovado em: 01/12/2014 